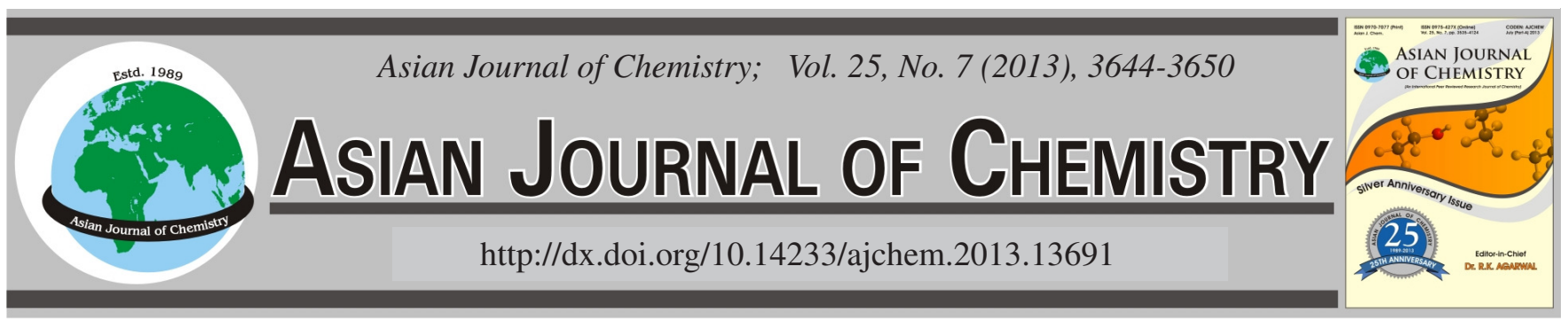

\title{
Determination of Geniposide in Rat Plasma by UPLC-MS
}

Yue Ding, Tong Zhang ${ }^{*}$, Jian-Sheng Tao, Chun-Rong Guo, Min-Yi Jin and Guang Ji

Shanghai University of Traditional Chinese Medicine, Shanghai 201203, P.R. China

*Corresponding author: Fax: +86 21 51322337; Tel: +86 21 51322318; E-mail: zhangtdmj@ hotmail.com; dingyue-2001@ hotmail.com

\begin{abstract}
A sensitive ultra performance liquid chromatography-mass spectrometry method has been developed and validated for the quantification of geniposide in rat plasma. Following solid-phase extraction, the analytes were separated on a UPLC BEH $\mathrm{C}_{18}$ column and analyzed in the selected ion recording with a positive ionization mode. The method was linear over the concentration range of $16.875-2700 \mathrm{ng} / \mathrm{mL}$. Intra-day and inter-day precisions and accuracy were all within $15 \%$ range. The lower limit of quantification was $16.875 \mathrm{ng} / \mathrm{mL}$. The recovery of geniposide was more than $65 \%$. The present method was successfully applied for the estimation of the pharmacokinetic parameters of geniposide following oral administration to rats at different three doses.
\end{abstract}

Key Words: Geniposide, Rat plasma, Method validation, UPLC-MS, Pharmacokinetics.

\section{INTRODUCTION}

Gardenia jasminoides Ellis, belonging to Rubiaceae family, is a widely used traditional Chinese medicine (TCM). Its dried ripe fruits, Fructus Gardenia (Zhi-zi in Chinese), have been extensively used to treat many diseases, such as hyperpyrexia, jaundice with urine abnormality, conjunctival congestion and contused wound, etc. ${ }^{1}$. Geniposide, a major iridoid glycoside in Zhi-zi, having some similar curative effects of Zhi-zi, can be used for liver protection and facilitating biliation at the doses of 50 or $100 \mathrm{mg} / \mathrm{kg}^{2-6}$. It has also been reported to possess antiinflammatory activity ${ }^{7}$ and antitumor activity ${ }^{5}$. The study indicates that geniposide possesses potential as a cancer chemopreventive agent against tumor promotion $^{8}$ and could ameliorate the treatment of ligament injuries by proliferating ligament fibroblasts and promoting the synthesis of collagen ${ }^{9}$. Another study mainly focus on diabetes shows that geniposide significantly decreases the blood glucose, insulin and TG levels in diabetic mice in a dosedependent manner. This compound also decreases the expression of GP and G6Pase at mRNA and immunoreactive protein levels, as well as enzyme activity. It is potential to be a new drug for diabetes ${ }^{10}$.

In previous pharmacokinetic study of geniposide, the determination of the concentration of geniposide in plasma has been done by high performance liquid chromatography (HPLC) with UV (ultraviolet) detection ${ }^{11,12}$ or tandem mass spectrometry (LC-MS/MS). As the HPLC-UV method is not sensible enough for the low concentration of geniposide in the biological samples with a limit of quantitation $c a .0 .1 \mu \mathrm{g} / \mathrm{mL}$. So the dose of geniposide in the pharmacokinetic study was always designed to be much higher than clinical dose. But there are also report of toxicity of geniposide at high dose $\mathrm{e}^{13}$. So more sensible methods have to be designed for pharmacokinetic study of geniposide. Another study reports a method to determine geniposide using LC/MS/MS via the formation of positive and negative ion adducts ${ }^{14,15}$. The formation of anionic adducts $\left(\left[\mathrm{M}+\mathrm{CH}_{3} \mathrm{COO}\right]^{-}\right)$and ammonium ions $([\mathrm{M}+$ $\left.\mathrm{NH}_{4}\right]^{+}$) could enhance the sensitivity of LC/MS detection of geniposide. The detection limits of using ammonium and acetate adducts are 1 and $5 \mathrm{ng} / \mathrm{mL}$, respectively.

In this study, we developed a rapid and sensitive ultra performance liquid chromatography-mass spectrometry (UPLC-MS) method to determine geniposide in rat plasma using an off-line solid-phase extraction (SPE). The analytes were assayed by quantifying the $[\mathrm{M}+\mathrm{Na}]^{+}$ions of geniposide at $\mathrm{m} / \mathrm{z} 411$ and peoniflorin (the internal standard, IS) at $\mathrm{m} / \mathrm{z}$ 503. No additives need be added into mobile phase solvents to form positive and negative adducts. This method enables geniposide to be measured down to $16.875 \mathrm{ng} / \mathrm{mL}$ in rat plasma. The LLOQ (lower limit of quantification) were lower 17 times than it by UV detection among $255 \mathrm{ng} / \mathrm{mL}^{16}$. The total run time of the method per sample was only $5 \mathrm{~min}$, which was almost 9 min shorter than HPLC-UV (The data in our study was not shown). To our best of knowledge, this is the first report of a UPLC-MS method for the determination of geniposide in rat plasma and its application to a pharmacokinetic study. 


\section{EXPERIMENTAL}

Geniposide used for pharmacokinetic study was isolated from Zhi-zi by our own laboratory. Its purity was over $98 \%$ determined by the high performance liquid chromatographyvariable wavelength detector (HPLC-VWD) analysis. Its chemical structure was identified by comparison of their UV, IR, ESI-MS, ${ }^{1} \mathrm{H}$ and ${ }^{13} \mathrm{C}$ NMR spectra with the standard compound purchased from the National Institute for the Control of Pharmaceutical and Biological Products (Shanghai, China). The standard compound of geniposide and peoniflorin with a purity of $98 \%$ was purchased from the National Institute for the Control of Pharmaceutical and Biological Products (Shanghai, China). HPLC-grade methanol and acetonitrile was purchased from Shanghai Ambrosia Pharmaceutical, Ltd. (Shanghai, China) and ultra-pure water was used for all analyses. Formic acid of analytical-reagent grade was purchased from Sinopharm Chemical Reagent Co., Ltd. (Shanghai, China). An AccuBONDII ODS- C $_{18}$ solid-phase extraction (SPE) cartridge (100 mg) was purchased from Agilent technology Corp. (Shanghai, China).

Instrument and analytical conditions: A waters ACQUITYTM ZQ with the power of ultra performance liquid chromatography (Waters, Milford, MA, USA) was used in the study. The chromatographic separation was achieved by using a Waters ACQUITY UPLC BEH $\mathrm{C}_{18}$ column $(2.1 \mathrm{~mm} \times 50$ $\mathrm{mm}, 1.7 \mathrm{~mm}$, Waters, Milford, MA, USA) maintained at $45^{\circ} \mathrm{C}$. The mobile phase consisted of acetonitrile (A)-water containing $0.1 \%$ formic acid (B) with a gradient elution $10 \%$ A over
0-3 min, 10-80\% A over 3-4 min and then returned to the initial condition. The injection volume was $2 \mu \mathrm{L}$.

Mass spectrometric conditions: Mass spectrometric detection was performed in positive ionization mode. Quantifications were performed in multiple channels in selected ion recording (SIR) mode using target ions at $[\mathrm{M}+\mathrm{Na}]^{+}$ions of geniposide at $\mathrm{m} / \mathrm{z} 411.0$ and peoniflorin at $\mathrm{m} / \mathrm{z}$ 503.0. The optimal MS parameters obtained were as follows: capillary $4.5 \mathrm{kV}$, source temperature $120{ }^{\circ} \mathrm{C}$ and desolvation temperature $350{ }^{\circ} \mathrm{C}$. The flow rate of desolvation gas was $600 \mathrm{~L} / \mathrm{h}$. All data collected in centroid mode were processed using MassLynx $^{\mathrm{TM}}$ NT 4.0 software with a QuanLynx ${ }^{\mathrm{TM}}$ program (Waters Corp., Milford, MA, USA). The optimized MS parameters are listed in Table- 1 and the scans for the geniposide and peoniflorin are shown in Fig. 1.

Preparation of standard and quality control samples: The stock standard solutions of geniposide and peoniflorin were prepared by dissolving accurately weighed individual compounds in methanol to give a final concentration of 2.70 and $3.67 \mathrm{mg} / \mathrm{mL}$, respectively. A series of standard working solutions at concentrations over $16.875-27,00 \mathrm{ng} / \mathrm{mL}$ for geniposide were obtained by further dilution of the standard stock solution with acetonitrile-water containing $0.1 \%$ formic acid (10:90; v/v) solution. Internal standard working solution $(367 \mathrm{ng} / \mathrm{mL})$ was prepared by diluting the internal standard stock solution with acetonitrile-water containing $0.1 \%$ formic acid (10:90; v/v) solution. All solutions were stored at $4{ }^{\circ} \mathrm{C}$ and brought to room temperature $\left(20^{\circ} \mathrm{C}\right)$ before use.

\begin{tabular}{ccccccc}
\multicolumn{7}{c}{ TABLE-1 } \\
\multicolumn{7}{c}{$\begin{array}{c}\text { SELECTED ION TRANSITIONS (m/z VALUES) AND OPTIMIZED MASS SPECTROMETRIC PARAMETERS FOR } \\
\text { UPLC/MS ANALYSIS OF GENIPOSIDE AND PEONIFLORIN IN SELECTED ION RECORDING (SIR) MODE }\end{array}$} \\
\hline Channals & $\mathrm{m} / \mathrm{z}$ & Capillary voltage $(\mathrm{kV})$ & Cone voltage $(\mathrm{V})$ & RF lens voltage (V) & Extractor (V) \\
\hline Geniposide & SIR of $1:[\mathrm{M}+\mathrm{Na}]^{+}$ & 411.00 & 4.5 & 50 & 0.5 & 3.9 \\
Peoniflorin & SIR of $2:[\mathrm{M}+\mathrm{Na}]^{+}$ & 503.00 & 4.5 & 50 & 0.5 & 3.9 \\
\hline
\end{tabular}

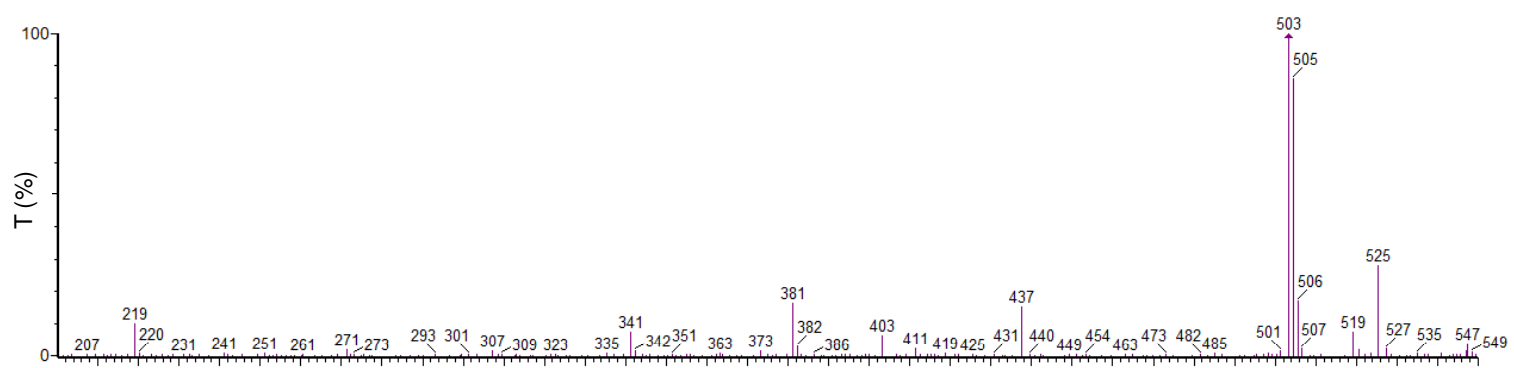

(A)

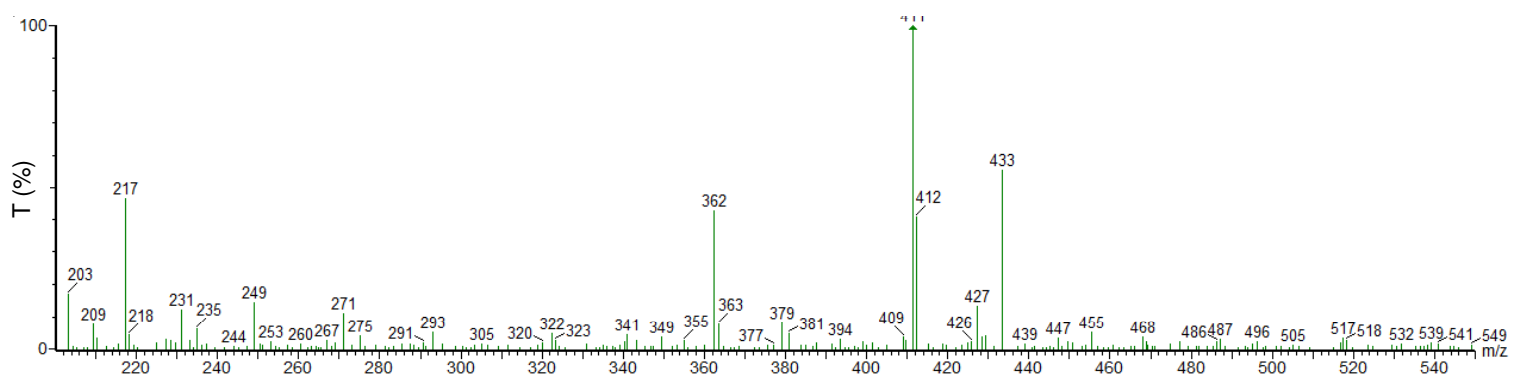

(B)

Fig. 1. Full-scan ion spectra of peoniflorin $\left(A\right.$, at $[\mathrm{M}+\mathrm{Na}]^{+}$ions of $\left.\mathrm{m} / \mathrm{z} 503.0\right)$ and geniposide $\left(\mathrm{B}\right.$, at $[\mathrm{M}+\mathrm{Na}]^{+}$ions of $\left.\mathrm{m} / \mathrm{z} 411.0\right)$ 
Blank rat plasma was collected from rats and pooled to get a sufficient volume to prepare calibration and quality control (QC) samples. The analytical standard and quality control samples were prepared by spiking the standard working solutions and internal standard working solution to blank rat plasma during validation and each experimental run for the pharmacokinetic studies. Calibration samples were made at the concentration of $16.875-27,00 \mathrm{ng} / \mathrm{mL}$ for geniposide with the same concentration of peoniflorin at $367 \mathrm{ng} / \mathrm{mL}$. Quality control samples were prepared at the concentrations of 84.375 , 1350 and $2025 \mathrm{ng} / \mathrm{mL}$ for geniposide with the same concentration of peoniflorin at $367 \mathrm{ng} / \mathrm{mL}$.

Sample preparation: All the plasma samples obtained after centrifugation were processed immediately. $200 \mu \mathrm{L}$ aliquot of plasma samples were transferred into polypropylene tubes (1.5 mL). Then $200 \mu \mathrm{L}$ peoniflorin solution $(367 \mathrm{ng} / \mathrm{mL})$ was added. The mixture was then vortexed for $1 \mathrm{~min}$.

The AccuBOND ODS- $\mathrm{C}_{18}$ solid-phase extraction (SPE) cartridge was conditioned using $1 \mathrm{~mL}$ of methanol and then $1 \mathrm{~mL}$ of water. The mixture was loaded onto the cartridge. Then the cartridges were washed with $1 \mathrm{~mL}$ of water at a flow rate not exceeding $2 \mathrm{~mL} / \mathrm{min}$. Subsequently the analytes were eluted using $3 \mathrm{~mL}$ of acetic ether into disposable test tubes. The eluate was evaporated to dryness under a constant stream of nitrogen at a temperature not exceeding $37^{\circ} \mathrm{C}$. The samples were reconstituted in $200 \mathrm{~mL}$ of acetonitrile-water containing $0.1 \%$ formic acid (10:90; v/v) solution. The reconstituted extraction was thoroughly mixed by vortexing and ultrasonication and then centrifuged again at 12,000 rpm for $10 \mathrm{~min}$. Only $2 \mathrm{~mL}$ aliquots was injected into the UPLC-MS system.

Specificity: The specificity of the method was investigated by analyzing blank plasma from six different rats, spiked plasma samples and plasma samples after oral administration. Chromatograms were examined to determine the presence of any endogenous constituents which might potentially interfere with the analysis of geniposide and peoniflorin.

Linearity and lower limit of quantification (LLOQ): The linear relationship of the method was evaluated by preparing seven different concentrations of samples in plasma using the previous extraction procedure. The calibration curves were established by plotting peak area ratios of geniposide to peoniflorin, versus the geniposide concentration. The calibration curve should meet the following criteria: not more than $20 \%$ deviation around LLOQ and not more than $15 \%$ deviation for standards above the LLOQ. The contents of geniposide in the test samples were calculated using the regression parameters obtained from the standard curve.

The LLOQ was defined as the lowest concentration giving a signal-to-noise ratio of at least 10-fold with acceptable accuracy within $20 \%$ deviation of the nominal concentration and precision below $20 \%$.

Precision, accuracy and extraction recovery: The intraday and inter-day precision and accuracy were investigated by determining quality control samples at three different concentrations (six replicates for each concentration level) over 3 consecutive days. The concentrations were calculated using calibration curves obtained daily. The precision of the method at each quality control concentration was expressed as the relative standard deviation (RSD) and the accuracy was described as relative error (RE), i.e., (determined concentrationnominal concentration $) /($ nominal concentration $) \times 100 \%$. The suitability of the precision and accuracy was assessed by the following criteria: the RSD should not exceed $15 \%$ and the accuracy should be within $15 \%$ of the actual values for quality control samples.

The extraction recoveries of geniposide were calculated by comparing the mean peak areas of geniposide obtained from six extracted low, medium and high quality control samples with those of six spike-after-extraction samples that represent $100 \%$ recovery. The extraction recovery of peoniflorin was estimated in the same manner in the medium quality control samples.

Matrix effect: The matrix effects on the ionization of geniposide and peoniflorin were assessed by comparing the peak areas dissolved in the blank sample (the final solution of blank plasma after extraction and dissolution) with that dissolved in the mobile phase. Three different concentration levels of geniposide were evaluated by analyzing the six samples obtained from different rats at each level.

Stability: The stability of geniposide in rats plasma was evaluated using quality control samples $(84.375,1350$ and $2025 \mathrm{ng} / \mathrm{mL}$ ) with five samples for each concentration. The stability validation of geniposide was investigated including freeze and thaw stability, short-term stability, long-term stability and post-preparative stability in the developed method. Freeze and thaw stability for geniposide in quality control samples was determined in three freeze-thaw cycles over 3 days at $20^{\circ} \mathrm{C}$. Short-term stability of geniposide in quality control samples after $24 \mathrm{~h}$ of storage at room temperature was evaluated. Post-preparative stability of geniposide during storage in the autosampler at $4{ }^{\circ} \mathrm{C}$ for $24 \mathrm{~h}$ was investigated. In addition, long-term stability of genipin in quality control samples after 30 days of storage at $\left(70^{\circ} \mathrm{C}\right)$ was also evaluated. Concentrations of geniposide in all samples were analyzed using freshly prepared calibration samples. The stability was described as relative error, i.e., (determined concentrationnominal concentration $) /($ nominal concentration $) \times 100 \%$. The RE should meet the following criteria: not more than $15 \%$ deviation for the four different concentration quality control samples.

Application of the assay to pharmacokinetic studies: Fifteen Sprague-Dawley rats, both male and female, weighing 180-220 g, were supplied by Laboratory Animal Center of the Shanghai University of traditional Chinese medicine. The rats were kept in an air-conditioned animal quarter at a temperature of $22-24{ }^{\circ} \mathrm{C}$ and a relative humidity of $50 \pm 10 \%$ and had access to the standard laboratory food and water. The rats were fasted and given free access to water for $12 \mathrm{~h}$ prior to experiment. The rats were divided into three groups at random. Three groups were given single dose of geniposide solution at 50 , 100 or $200 \mathrm{mg} / \mathrm{kg}$ of body weight by gavage into the stomach using a blunt ended needle. Geniposide solution for oral administration was prepared by dissolving the powder of geniposide with isotonic sodium chloride solution. The rats were fasted for the first $2 \mathrm{~h}$ with free assess to water after dosing. About $400 \mathrm{~mL}$ blood samples were collected from the 
suborbital veniplex before intragastric gavage and after that at $2,5,10,20,30,45,60,90,120,180,240,360$ and $600 \mathrm{~min}$, transferred to heparinized tubes and centrifuged at $6000 \mathrm{rpm}$ for $10 \mathrm{~min}$ to separate out plasma. The plasma was then transferred to clean tubes and stored at $-20^{\circ} \mathrm{C}$ for preservation until analysis. During routine analysis, each analytical run included six blank plasma, a set of calibration samples, a set of quality control samples and unknowns. Animal experiments were carried out in accordance with the local institutional guidelines for animal care of Shanghai University of traditional Chinese medicine.

Statistical analysis: To determine the pharmacokinetic parameters of geniposide, the concentration-time data were analyzed by DAS Software (ver. 2.0, China State Drug Administration). Data were expressed as mean \pm SD.

\section{RESULTS AND DISCUSSION}

Specificity: Specificity was assessed by comparing the chromatograms of six different batches of blank rat plasma with spiked plasma samples and plasma samples after oral administration. Typical chromatograms of the blank plasma samples, spiked plasma samples and plasma samples after oral administration are given in Fig. 2. The retention times of geniposide and peoniflorin were about were 1.62 and 2.53 min, respectively. Endogenous peaks at the retention time of geniposide and peoniflorin were not observed for any of the blank rat plasma batches indicating no significant endogenous interference in the selected ion recording (SIR) mode for the analytes during the detections.

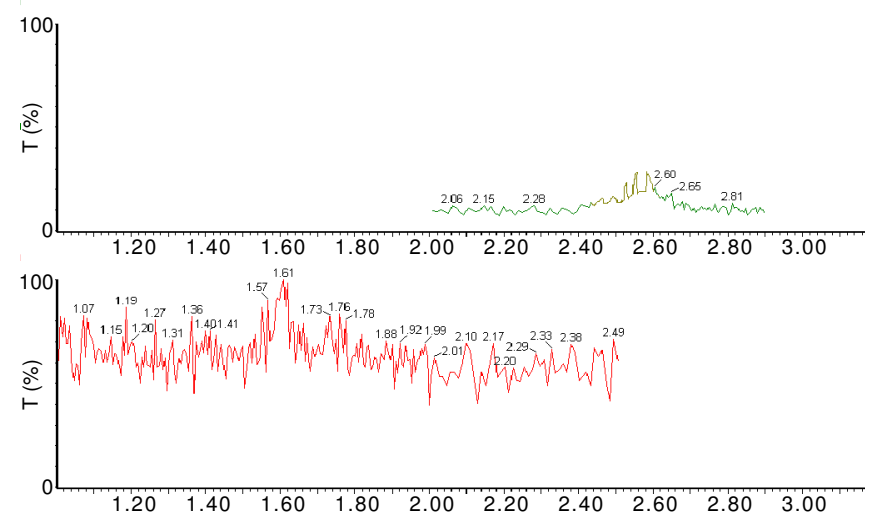

(A)

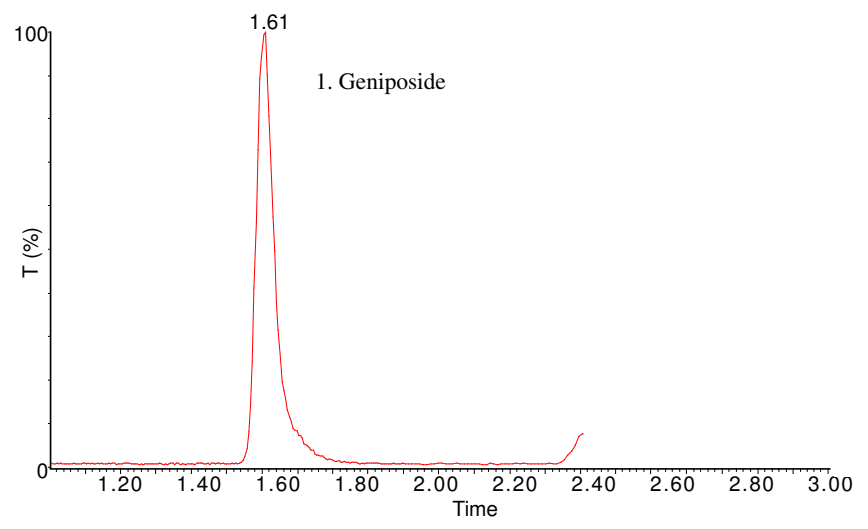

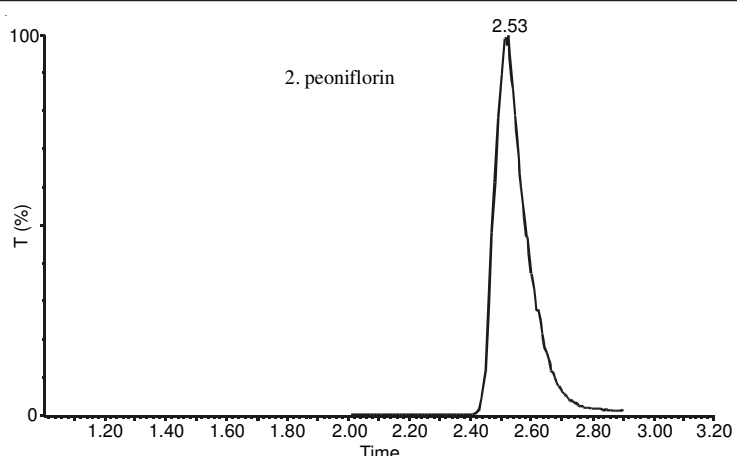

(B)
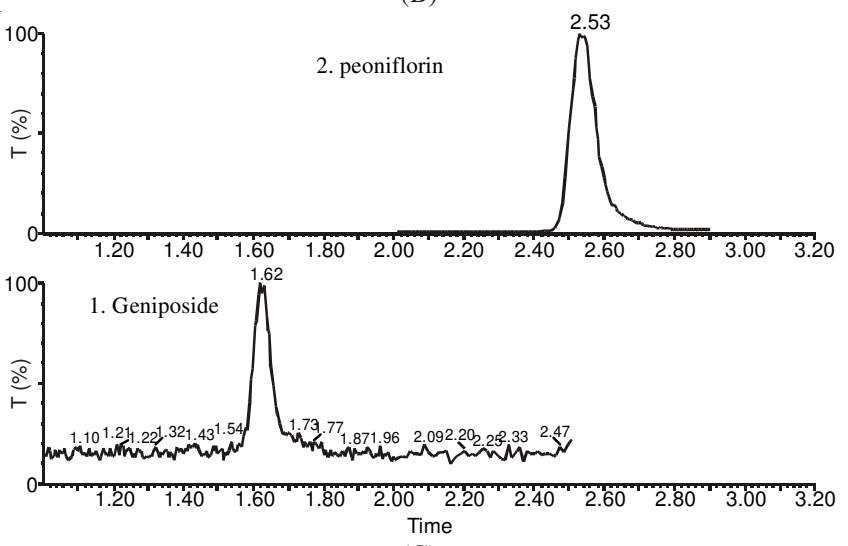

(C)

Fig. 2. Extracted ion chromatograms of blank plasma (A), spiked plasma samples (B) and plasma samples after oral administration (C). The peak designation and its retention time were (1) geniposide, 1.62 min and (2) peoniflorin, $2.53 \mathrm{~min}$

Linearity and lower limit of quantifications: The calibration curve of geniposide was constructed by plotting the peak-area ratio of geniposide to peoniflorin (y) versus geniposide concentration $(\mathrm{ng} / \mathrm{mL})$ in spiked blank rat plasma(x). The peak-area ratios of geniposide to peoniflorin in rat plasma varied linearly with concentration over the range: $16.875,84.375,337.5,675,1350,2025,2700 \mathrm{ng} / \mathrm{mL}$. The calibration model was selected based on the analysis of the data by linear regression with weighting factors $\left(1 / \mathrm{x}, 1 / \mathrm{x}^{2}\right.$ and $1 / x)$. The best linear fit and least-squares residuals for the calibration curve were achieved with a $1 / \mathrm{x}^{2}$ weighing factor, giving a mean linear regression equation for the calibration curve of: $y=0.0009 x-0.0017$. The mean correlation coefficient of the weighted calibration curve generated during the validation was 0.999 . The LLOQ of geniposide was 16.875 $\mathrm{ng} / \mathrm{mL}(\mathrm{RSD} \%=6.5 \%, \mathrm{n}=5$, signal-to-noise $>10 / 1)$. The mean LOD of geniposide in our assay is estimated at $5.0 \mathrm{ng} /$ $\mathrm{mL}$ which produced a signal-to-noise of $3 / 1$. Concentrations were back-calculated from nominal concentrations and were summarized in Table-2.

Accuracy and precision: The intra-day and inter-day precision and accuracy data at three concentrations of geniposide were listed in Table-3. The intra-day precision (RSD \%) ranged from 1.4 to $7.2 \%$ and the inter-day precision ranged from 6.8 to $9.9 \%$. The intra-day accuracy (expressed as per cent of nominal values) ranged from 1.9 to $9.4 \%$ and the inter-day accuracy ranged from $-7.0 \%$ to $13.9 \%$. The results above demonstrated that the method established has a satisfactory accuracy, precision and reproducibility. 


\begin{tabular}{cccc}
\hline \multicolumn{5}{c}{ TABLE-2 } \\
$\begin{array}{ccc}\text { CALIBRATION STANDARDS OF GENIPOSIDE IN RAT } \\
\text { PLASMA CALIBRATION CURVES }(\mathrm{n}=5)\end{array}$ \\
\hline $\begin{array}{c}\text { Nominal conc. } \\
(\mathrm{ng} / \mathrm{mL})\end{array}$ & $\begin{array}{c}\text { Measured concentration } \\
(\mathrm{ng} / \mathrm{mL})(\text { mean } \pm \text { SD) }\end{array}$ & $\begin{array}{c}\text { Deviation } \\
(\%)\end{array}$ & $\begin{array}{c}\text { RSD } \\
(\%)\end{array}$ \\
\hline 16.875 & $16.574 \pm 0.964$ & -1.8 & 5.8 \\
84.375 & $92.621 \pm 1.342$ & 9.8 & 1.4 \\
337.5 & $326.97 \pm 10.80$ & -3.1 & 3.3 \\
675 & $730.65 \pm 16.84$ & 8.2 & 2.3 \\
1350 & $1284.55 \pm 92.02$ & -4.8 & 7.2 \\
2025 & $1925.33 \pm 43.53$ & -4.9 & 2.3 \\
2700 & $2658.40 \pm 136.73$ & -1.5 & 5.1 \\
\hline
\end{tabular}

\begin{tabular}{cccc}
\multicolumn{5}{c}{ TABLE-3 } \\
\multicolumn{4}{c}{$\begin{array}{c}\text { ACCURACY AND PRECISION FOR THE } \\
\text { ANALYSIS OF GENIPOSIDE }(\mathrm{n}=5)\end{array}$} \\
\cline { 1 - 2 } QC $(\mathrm{ng} / \mathrm{mL})$ & $\begin{array}{c}\text { Accuracy } \\
\text { deviation }(\%)\end{array}$ \\
\cline { 2 - 3 } & Precision \\
\hline \multicolumn{4}{c}{ Intra-day } \\
\hline 84.375 & $92.621 \pm 1.342$ & 1.4 & 9.4 \\
1350 & $1284.55 \pm 92.02$ & 7.2 & 5.2 \\
2025 & $1925.33 \pm 43.53$ & 5.1 & 1.9 \\
\hline \multicolumn{4}{c}{ Inter-day } \\
\hline 84.375 & $96.101 \pm 9.531$ & 9.9 & 13.9 \\
1350 & $1255.9 \pm 84.8$ & 6.8 & -7.0 \\
2025 & $2082.3 \pm 187.6$ & 9.0 & 9.0 \\
\hline
\end{tabular}

Recovery: The recovery of geniposide and peoniflorin from rat plasma was shown in Table- 4 . The mean recoveries of geniposide were more than $80 \%$ at three concentration levels.

\begin{tabular}{ccc}
\multicolumn{3}{c}{ TABLE-4 } \\
RECOVERY OF GENIPOSIDE AND \\
PEONIFLORIN FROM RAT PLASMA (n = 5) \\
\hline Concentration $(\mathrm{ng} / \mathrm{mL})$ & Recovery (mean \pm SD \%) & RSD $(\%)$ \\
\hline \multicolumn{3}{c}{ Geniposide } \\
\hline 84.375 & $86.1 \pm 3.8$ \\
1350 & $90.7 \pm 7.2$ & 2.5 \\
2025 & $85.1 \pm 6.4$ & 6.5 \\
\hline \multicolumn{3}{c}{ Peoniflorin } \\
\hline 367 & $78.9 \pm 5.4$ \\
\hline
\end{tabular}

Matrix effects: The matrix effects on the ionization of geniposide and peoniflorin were assessed by comparing the peak areas dissolved in the blank samples with low, mid and high concentrations of geniposide $(84.375,1350,2700 \mathrm{ng} /$ $\mathrm{mL})$ and peoniflorin $(367 \mathrm{ng} / \mathrm{mL}, \mathrm{n}=5$, respectively) with that dissolved in the mobile phase. The ratios of the peak area resolved in the after-extraction blank sample with that resolved in the mobile phase of geniposide and peoniflorin were not $<75$ and $>120 \%$. These results confirmed that the evaluated method was free from any matrix effects.

Stability: Quality control samples of geniposide at three concentrations $(84.375,1350$ and $2025 \mathrm{ng} / \mathrm{mL}$ ) were used for stability experiments (Table-5). The stability of geniposide was tested under four different conditions. Geniposide was shown to be stable (RE range from -4.6 to $5.0 \%$ ) in rat plasma for 30 days when stored at $-70^{\circ} \mathrm{C}$. After three freeze-thaw cycles in rat plasma, geniposide was shown to be stable (RE range from -3.8 to $8.5 \%$ ). In our experiment, it was also observed that the unprocessed quality control samples were stable (RE range from 3.6-5.0 \%) at room temperature for $24 \mathrm{~h}$. After extraction, geniposide was found to be stable (RE range from -2.5 to $10.0 \%$ ) in the reconstitution solution at $4{ }^{\circ} \mathrm{C}$ for $24 \mathrm{~h}$. Taking all the above observations into consideration, geniposide was stable in stored plasma samples for up to 90 days at $-70{ }^{\circ} \mathrm{C}$, at room temperature for $4 \mathrm{~h}$, through three freeze-thaw cycles or in processed extracts at $4{ }^{\circ} \mathrm{C}$ for $24 \mathrm{~h}$. This study also indicated that the plasma samples in the pharmacokinetics study should be extracted within $24 \mathrm{~h}$ after collection at room temperature or stored in a freezer at $-70^{\circ} \mathrm{C}$ immediately for later analysis.

Application to pharmacokinetic study: This UPLC-MS method developed has been used successfully in the pharmacokinetic studies in rats. The mean plasma concentration-time curves of geniposide among the fifteen rats in three group with different dose of geniposide $(50,100$ or $200 \mathrm{mg} / \mathrm{kg}$, after oral administration) were shown in Fig. 3. The concentrationtime curves of geniposide in rat plasma fitted a one-compartment model with a weighting factor of 1 . The pharmacokinetic results were processed using drug and statistics (DAS) version 2.0 software. The pharmacokinetic parameters of geniposide were presented in Table-6. For oral administration, the drug concentration was below LLOQ or LOD for the samples collected after $240 \mathrm{~min}$ in the $50 \mathrm{mg} / \mathrm{kg}$ group or after $600 \mathrm{~min}$ in the $200 \mathrm{mg} / \mathrm{kg}$. $\mathrm{C}_{\max }$ is mainly depended to the dose with a coefficient of correlation of 0.9976 in the three group. But $\mathrm{t}_{1 / 2}, \mathrm{AUC}_{0-\infty}$ and MRT are not proportional to the dose and they are depended to the dose with a coefficient of

TABLE-5

STABILITY OF QUALITY CONTROL SAMPLES OF GENIPOSIDE IN RAT PLASMA UNDER DIFFERENT STORAGE CONDITIONS ( $\mathrm{n}=5$ )

\begin{tabular}{|c|c|c|c|c|}
\hline \multirow{2}{*}{ Storage conditions } & \multicolumn{4}{|c|}{ Geniposide concentration $(\mathrm{ng} / \mathrm{mL})$} \\
\hline & Added & Found (mean) & $\operatorname{RSD}(\%)$ & $\operatorname{RE}(\%)$ \\
\hline \multirow{3}{*}{ Three freeze/thaw cycles } & 84.375 & 91.534 & 7.2 & 8.5 \\
\hline & 1350 & 1298.31 & 6.2 & -3.8 \\
\hline & 2025 & 2075.1 & 4.6 & 2.5 \\
\hline \multirow{3}{*}{ Post-processing stability for $24 \mathrm{~h}$} & 84.375 & 87.345 & 1.9 & 3.5 \\
\hline & 1350 & 1485.31 & 4.9 & 10.0 \\
\hline & 2025 & 1975.23 & 5.9 & -2.5 \\
\hline \multirow{3}{*}{ Short-term stability for $24 \mathrm{~h}$} & 84.375 & 88.567 & 6.0 & 5.0 \\
\hline & 1350 & 1398.2 & 7.1 & 3.6 \\
\hline & 2025 & 2103.6 & 6.4 & 3.9 \\
\hline \multirow{3}{*}{ Long-term stability for 30 days } & 84.375 & 88.568 & 4.9 & 5.0 \\
\hline & 1350 & 1301.2 & 6.6 & -3.6 \\
\hline & 2025 & 1931.2 & 5.8 & -4.6 \\
\hline
\end{tabular}




\begin{tabular}{|c|c|c|c|}
\hline \multicolumn{4}{|c|}{$\begin{array}{c}\text { TABLE-6 } \\
\text { PHARMACOKINETIC PARAMETERS OF GENIPOSIDE FOLLOWING } \\
\text { A SINGLE ORAL DOSE OF } 50,100 \text { or } 200 \mathrm{mg} / \mathrm{kg}(\text { MEAN } \pm \mathrm{SD}, \mathrm{n}=5)\end{array}$} \\
\hline Pharmacokinetic parameters & $50(\mathrm{mg} / \mathrm{Kg})$ & $100(\mathrm{mg} / \mathrm{Kg})$ & $200(\mathrm{mg} / \mathrm{Kg})$ \\
\hline $\mathrm{C}_{(\max )}(\mathrm{ng} / \mathrm{mL})$ & $1127.2 \pm 77.7$ & $1543.1 \pm 93.7$ & $2231.2 \pm 138.0$ \\
\hline $\mathrm{T}($ peak) (min) & $18 \pm 4.4$ & $20 \pm 0$ & $20 \pm 0$ \\
\hline $\mathrm{t}_{1 / 2}(\min )$ & $33.5 \pm 4.1$ & $66.8 \pm 14.9$ & $63.1 \pm 10.6$ \\
\hline MRT (min) & $79.2 \pm 11.3$ & $113.9 \pm 9.6$ & $128.4 \pm 18.9$ \\
\hline $\operatorname{AUC}_{0-\mathrm{t}}[(\mathrm{ng} / \mathrm{mL}) \times \mathrm{min}]$ & $82651.6 \pm 9358.4$ & $175641.8 \pm 44410.1$ & $250071.4 \pm 13757.1$ \\
\hline $\operatorname{AUC}_{0-\infty}[(\mathrm{ng} / \mathrm{mL}) \times \mathrm{min}]$ & $83189.0 \pm 9366.6$ & $177030.9 \pm 45059.2$ & $251965.0 \pm 14060.3$ \\
\hline $\operatorname{ke}(1 / \mathrm{min})$ & $0.021 \pm 0.002$ & $0.011 \pm 0.003$ & $0.011 \pm 0.002$ \\
\hline $\mathrm{CL} / \mathrm{F}(\mathrm{s})[\mathrm{mL} / \mathrm{g} / \mathrm{min}]$ & $607.0 \pm 66.8$ & $599.2 \pm 171.8$ & $795.7 \pm 43.3$ \\
\hline
\end{tabular}

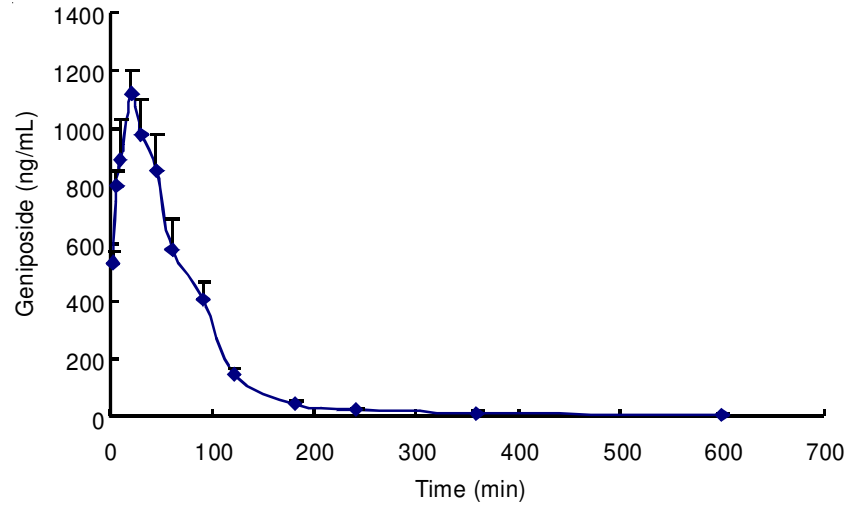

(A)

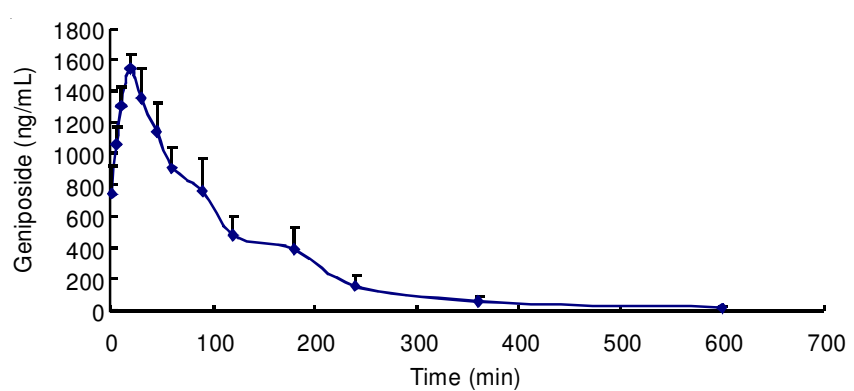

(B)

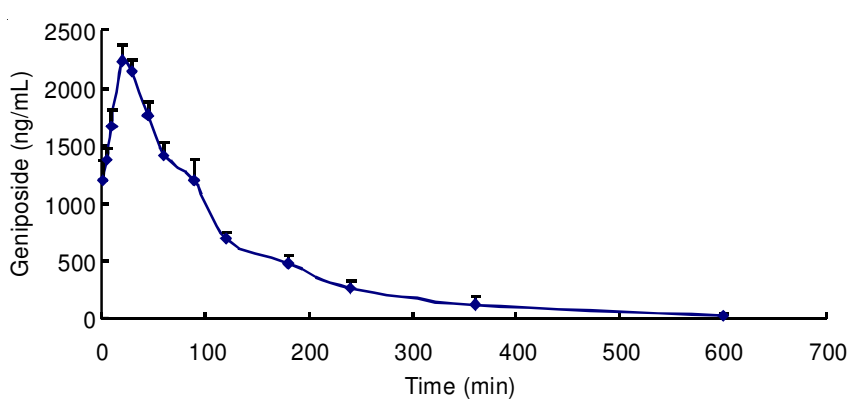

(C)

Fig. 3. Mean plasma concentration of geniposide vs. time in rat plasma. (A) Oral administration of $50 \mathrm{mg} / \mathrm{kg}$, (B) oral administration of $100 \mathrm{mg} / \mathrm{kg}$, (C) oral administration of $200 \mathrm{mg} / \mathrm{kg}$. Each point and bar represent the mean \pm SD $(n=6)$

correlation of 0.4702 for $\mathrm{t}_{1 / 2}, 0.9686$ for $\mathrm{AUC}_{0-\infty}$ and 0.832 for MRT.

Firstly, we used HPLC with UV detection to detect geniposide in rat plasma. However, the sensitivity was too low to detect the concentrations of geniposide in rat plasma. The LLOQ of HPLC with UV detection was $c a .142 \mathrm{ng} / \mathrm{mL}$. While for UPLC/MS, the LLOQ was $16.876 \mathrm{ng} / \mathrm{mL}$. Therefore, this
UPLC/MS method established made it possible for fewer samples required and the extended calibration curve made it easy to perform animal pharmacokinetic studies.

Chromatographic separation was performed by gradient elution, since it markedly prolongs the column life, improves the chromatographic peak shapes, increases the response and shortens the elution time. The mobile phase was composed of acetonitrile-water (containing $0.1 \%$ formic acid). The addition of a small amount of formic acid to the mobile phase proved to have positive effects on the sensitivity.

To reduce contamination of the mass spectrometer, a diverting valve located between the analytical column and the mass spectrometer was used. It directed the UPLC liquid flow to a waste container during the first $1 \mathrm{~min}$ of the chromatographic separation and then allowed the eluate to pass through the mass spectrometer only during the analyte elution (1-3 $\min$ ).

MS examination of geniposide and peoniflorin(IS) standard solutions in positive and negative ionization modes by direct full scan method revealed that the signals obtained from the electrospray ionization source in positive mode had a good resolution and high intensity to permit quantitative measurement. In the positive mode, the predominantly protonated molecules $[\mathrm{M}+\mathrm{Na}]^{+}$at $\mathrm{m} / \mathrm{z} 411$ and 503 were selected for analyze geniposide and peoniflorin, respectively. Two channels were used for recording. Channel 1 was for geniposide with a typical retention time of $1.61 \mathrm{~min}$ and channel 2 was for the peoniflorin with a typical retention time of $2.53 \mathrm{~min}$. As shown in Fig. 3, both geniposide and peoniflorin were well separated with excellent peak shapes. The total run time was only 3 min per sample, which met the requirement for a high sample throughput.

In order to maximize recoveries and facilitate the sample preparation, different sample preparation methods were tested. Firstly, protein precipitation and liquid-liquid extraction were carried out during sample preparation. It was much simpler and less time-consuming for liquid-liquid extraction, matrix effects could not be reduced because of the presence of co-eluting compounds and the recovery of geniposide was lower than $60 \%$. Protein precipitation method concentrated the plasma samples, thus offered higher sensitivity than liquidliquid extraction, but analytes were interfered by endogenous substances. Then we found the solid-phase extraction method could produce a relative clean sample with the recoveries of geniposide and peoniflorin higher than $66.1 \%$. For solid-phase extraction, methanol, acetonitrile and ethyl acetic were investigated as elution solvent. Results showed that ethyl acetate was 
the best elution solvent with high absolute recoveries of geniposide and peoniflorin. And no interferences were found at the retention times of geniposide and peoniflorin. In addition, the dose of ethyl acetate was investigated. The result showed the recoveries of applying $3 \mathrm{~mL}$ of ethyl acetate for extraction were about 1.5 times of that with using $1 \mathrm{~mL}$ of extraction solvent and were similar to the use of $4 \mathrm{~mL}$. Considering the recovery efficiency and consuming time of blow-drying samples, $3 \mathrm{~mL}$ of ethyl acetate was employed. Based on these results, we established the sample extraction procedure.

It was found that the best fit pharmacokinetic model to estimate the pharmacokinetic parameters was single compartment model with weight of 1 for oral administration by DAS software. which were in parallel with the literature (Lu et al., 2004, Jiang et al., 2007). The pharmacokinetic parameters showed $\mathrm{C}_{\max }$ was mainly depended to the doses with a coefficient of correlation of 0.9976 in the three group. But $\mathrm{t}_{1 / 2}, \mathrm{AUC}_{0-\infty}$ and MRT were non-proportional to the doses of oral administration. Those results indicated the absorption of geniposide in rat by oral administration may be a nonlinear process. And the absorption of geniposide in rat was so fast that geniposide could be detected at the first sampling time of 2 min after oral administration and the maximum concentration of geniposide appeared at the fourth sampling time of $20 \mathrm{~min}$ after oral administration.

\section{Conclusion}

The study firstly reported an UPLC-MS quantitative method for simultaneous determination of geniposide in rat plasma samples after oral administration. It is a rapid, sensitive method to provide a useful alternative for analysis of the pharmacokinetics of geniposide in plasma samples. The method results in high sensitivity with a lower limit of quantitation of 16.875 $\mathrm{ng} / \mathrm{mL}$, wide linearity, specificity and no interferences from endogenous substances. The total run time was only $3 \mathrm{~min}$ per sample and the plasma sample pretreatment was a one- step SPE procedure. It is superior to any other reported methods to evaluate the pharmacokinetics of geniposide in rats.

\section{ACKNOWLEDGEMENTS}

This work was financially supported by the programs of National Natural Science Foundation of China (Project No: 81173561), Foundation of the Ministry of Education of China (NCET-10-0944) and the Shanghai Municipal Education Commission (Project No. 2010JW21, J50302).

\section{REFERENCES}

1. Chinese Pharmacopoeia Committee Editing. Chinese Pharmacopoeia, Chemical and Industrial Publisher, Part I, 2005 edition, p. 173 (2005).

2. J. Peng, Z.Y. Qian, T.Z. Liu, S.Y. Rao and B. Qu, Chin. J. New Drugs, 12, 105 (2003).

3. Z.J. Zhu, Z.Y. Qiao and C.Y. Bao, Chin. Tradit. Herb. Drugs, 32, 530 (2001).

4. Q.S. Yao, G.L. Zhou and Y.Q. Zhu, China J. Chin. Mater. Med., 8, 493 (1991).

5. H.Y. Hsu, E.J. Yang, S.Y. Lin and C.C. Lin, Cancer Lett., 113, 31 (1997).

6. Y. Suzuki, K. Kondo, Y. Ikeda and K. Umemura, Planta Med., 67, 807 (2001).

7. H.J. Koo, K.H. Lim, H.J. Jung and E.H. Park, J. Ethnopharmacol., 103, 496 (2006).

8. M.J. Lee, J.D. Hsu and C.J. Wang, Anti Cancer Res., 15, 411 (1995).

9. Q.C. Chen, W.Y. Zhang, H. Kim, I.S. Lee, Y. Ding, U.J. Youn, S.M. Lee, M. Na, B.S. Min and K. Bae, Phytother. Res., 24S, S1 (2010).

10. S.Y. Wu, G.F. Wang, Z.Q. Liu, J.J. Rao, L. Lu, W. Xu, S.G. Wu and J.J. Zhang, Acta Pharmacol. Sin., 30, 202 (2009).

11. X.H. Lu, L.T. Zhang, Z.F. Yuan, H. Wu and W. Guo, Chin. J. Pharm. Anal., 24, 140 (2004).

12. G. Ye, H.Y.Zhu, H.L. Zhao, B. Xu and C.G. Huang, Biomed. Chromatogr., 20, 743 (2006).

13. D.F. Li, L. Cheng, H.W. Wu, G.Z. Zong, Y. Zhang and H.J. Yang, Chin. J. Exp. Tradit. Med. Formula, 13, 31 (2007).

14. Shau-Chun Wang, Chih-Ming Huang and Tung-Hu Tsai, Microchem. J., 86, 174 (2007).

15. S.C. Wang, H.J. Liao, W.C. Lee, C.M. Huang and T.H. Tsai, J. Chromatogr. A, 1212, 68 (2008).

16. L. Jiang, X. Huang, F. Qin, W.J. Su, P. Ren and W.F. Tang, Pharmacol. Clin. Chin. Mater. Med., 23, 13 (2007). 